\title{
ANALISIS ENKRIPSI CITRA DIGITAL MENGGUNAKAN ALGORITMA LOGISTIC MAP DENGAN ALGORITMA KOMPRESI LAMPEL-ZIV-WELCH (LZW)
}

\author{
Sudirman \\ STMIK \& AMIK Logika Medan \\ Jl. K.L.Yos Sudarso No. 374-C \\ sudirmanart@gmail.com
}

\begin{abstract}
Abstrak-Penggunaan data berupa file citra sudah semakin luas diberbagai bidang. Oleh karena itu pengamanan terhadap file citra dari akses orang-orang yang tidak berhak menjadi hal yang penting. Berbagai macam teknik untuk mengamankan data atau informasi telah banyak dikembangkan salah satunya adalah teknik kriptografi. Selain dari segi keamanan, yang perlu diperhatikan jika bekerja dengan file citra adalah ukuran file yang dominan besar. Teknik kriptografi dan teknik kompresi menjadi hal penting didalam pengolahan citra. Algoritma Logistic Map merupakan algoritma berbasis Chaos yang mempunyai sensitivitas yang dapat diandalkan didalam mengenkripsi citra. Lempel Ziv Welch merupakan algoritma kompresi yang bersifat loseless yang dapat mengkompresi citra tanpa ada kehilangan unsur pixel didalamnya atau citra hasil kompresi identik dengan citra aslinya. Citra akan di enkripsi terlebih dahulu baru kemudian dilakukan teknik kompresi dengan algoritma Lempel Ziv Welch. Hasil kompresi yang dihasilkan tidak lagi dalam bentuk gambar tetapi dalam bentuk file dengan ekstensi *.mat. Perbedaan format file dari citra menjadi file yang bukan citra dapat membantu menghindari perhatian kriptanalisis.
\end{abstract}

Keywords-Kriptografi, Kompresi, Logistic Map, Lempel Ziv Welch, Citra.

\section{PENDAHULUAN}

Citra (image) atau gambar merupakan salah satu bentuk multimedia yang penting. Citra menyajikan informasi secara visual dan informasi yang disajikan oleh sebuah citra lebih kaya daripada yang disajikan secara tekstual.

Citra yang disimpan atau yang akan ditransmisikan dalam bentuk plainimage rentan dalam bentuk penyadapan dan pencurian, seperti yang diungkapkan oleh Chin-Chen Chang [5]. Menyebutkan bahwa jumlah kejahatan dibidang teknologi informasi telah meningkat akhir-akhir ini. Tingkat keamanan menggunakan media gambar telah menjadi topik penting dalam dunia komputer. Salah satu kelemahan penggunaan media informasi media gambar adalah mudah dimanipulasi oleh pihak-pihak yang berkepentingan lain didalamnya. Terlebih jika informasi berupa file gambar tersebut bersifat rahasia, seperti data-data pribadi, dokumen kenegaraan atau dokumen medis rumah sakit.

Untuk mengatasi masalah tersebut, teknik kriptografi sangat diperlukan untuk melakukan enkripsi data. Salah satu algoritma enkripsi yang popular digunakan didalam mengenkripsi citra adalah algoritma enkripsi berbasis chaos, salah satunya adalah algoritma Logistic Map [3]. Chaos digunakan didalam kriptografi karena tiga alasan : (1) sifat chaos yang sensitive terhadap nilai awal, (2) chaos berkelakuan acak, (3) Nilai-nilai chaos tidak mempunyai periode [4].
Selain algoritma kriptografi yang digunakan untuk melakukan enkripsi, algoritma kompresi juga dapat berperan dalam melakukan teknik pengacakan pada citra. Proses encoding pada kompresi citra dapat merubah posisi pixel-pixel pada citra. Dimana pada proses encoding umumnya akan mengurangi redudansi dari data-data yang terdapat didalam citra. Sehingga posisi pixel-pixel pada citra akan berubah dari posisi awal sebelum dilakukan proses kompresi.

Algoritma Lempel-Ziv-Welch (LZW) yang merupakan algoritma kompresi lossless yang menghasilkan kompresi cukup baik diantara algoritma lossless yang ada. Algoritma ini melakukan kompresi dengan menggunakan dictionary, dimana fragmenfragmen teks digantikan dengan indeks yang diperoleh dari sebuah kamus. Pendekatan algoritma ini bersifat adaktif dan efektif karena banyak karakter dapat dikodekan dengan mengacu kepada string yang telah muncul sebelumnya dalam teks [2].

Pada penelitian ini akan dilakukan pengabungan didalam melakukan pengamanan citra (image) yaitu teknik kriptografi dan teknik kompresi.

\section{METODOLOGI PENELITIAN}

\section{A. Logistic Map}

Logistic map merupakan sistem chaos yang paling sederhana yang berbentuk persamaan iteratif sebagai berikut :

$$
x_{i+1}=\mu x_{i}\left(1-x_{i}\right)
$$


Nilai $\chi_{i}$ yaitu antara $0 \leq \chi_{i} \leq 1$, sedangkan $\mu$ adalah parameter fungsi yang menyatakan laju pertumbuhan yang nilainya $0 \leq \mu \leq 4$. Logistic map akan bersifat chaos bilamana $3.5699456 \leq \mu \leq 4$ (Hongmai, 2010). Nilai awal persamaan iterasi adalah $x_{0}$. Perubahan sedikit saja pada nilai awal ini (misalnya sebesar $10^{-10}$ ) akan menghasilkan nilai chaos yang berbeda secara signifikan setelah logistic map diiterasi pada sejumlah kali. Didalam sistem kriptografi nilai awal $x_{0}$, dan parameter $\mu$ berperan sebagai kunci rahasia. Nilainilai acak yang dihasilkan dari persamaan (1) tidak pernah berulang kembali sehingga logistic map dikatakan tidak mempunyai periode.

Nilai-nilai acak yang dihasilkan logistic map tidak dapat langsung dioperasi modulokan karena masih berupa bilangan rill antara 0 dan 1 [1]. Nilai tersebut harus di transformasikan menjadi nilai integer. Transformasi yang sederhana adalah dengan mengambil bagian decimal dari bilangan riil, membuang angka nol yang berada didepan bilangan, lalu mengektrak $t$ digit integer. Contoh, $x_{i}=$ 0.004276501 dan $\mathrm{t}=4$, maka diambil bagian decimal dari $x_{i}$ tersebut 004276501 , kemudian buang nol yang berada didepan bilangan menjadi 4276501 , ektrak 4 digit integer yaitu 4276. Inilah keytream yang akan dimodulokan. Karena nilai-nilai piksel berada dalam rentang integer [0,255], maka keystream harus dimodulokan dengan 256 [3]. Jadi pada contoh ini $k_{i}=$ $4276 \bmod 256=180$.

\section{B. Lempel Ziv Welch (LZW)}

Fdsf Lempel Ziv Welch (LZW) adalah algoritma kompresi loseless yang ditemukan oleh Abraham Lempel, Jacob Ziv, dan Terry Welch. Diciptakan oleh Welch tahun 1984 sebagai implementasi dan pengembangan algoritma LZ78 yang diciptakan oleh Lempel dan Ziv pada tahun 1978. Algoritma LZW dirancang untuk cepat dalam implementasi tetapi biasanya tidak optimal karena hanya melakukan analisis pada data.

Algoritma LZW melakukan kompresi dengan menggunakan dictionary, dimana fragmen-fragmen teks digantikan dengan indeks yang diperoleh dari sebuah kamus. Prinsip sejenis juga digunakan dalam kode Braille, dimana kode-kode khusus digunakan untuk mempresentasikan kata-kata yang ada. Pendekatan ini bersifat adaptif dan efektif karena banyak karakter bisa dikodekan dengan mengacu pada string yang telah muncul sebelumnya dalam teks.

Prinsip kompesi tercapai jika referensi dalam bentuk pointer dapat disimpan dalam jumlah bit yang lebih dibandingkan string aslinya. Sebagai contoh, string "ABBABABAC" akan dikompresi dengan LZW. Isi dictionary pada awal proses diset dengan tiga karakter dasar yang ada: "A", "B", "C". Tahapan proses kompresi ditunjukkan pada Tabel I.
TABEL I

TAHAPAN PROSES KOMPRESI

\begin{tabular}{|l|l|l|l|l|}
\hline Step & Posisi & Karakter & \multicolumn{1}{|c|}{ Dictionary } & Output \\
\hline 1 & 1 & A & [4] A B & A \\
\hline 2 & 2 & B & {$[5]$ B B } & B \\
\hline 3 & 3 & B & {$[6]$ B A } & B \\
\hline 4 & 4 & A & [7] A B A & A B \\
\hline 5 & 6 & C & [8] A B A C & A B A \\
\hline 6 & 9 & C & -- & C \\
\hline
\end{tabular}

Kolom posisi menyatakan posisi sekarang dari stream karakter dan kolom karakter menyatakan karakter yang terdapat pada posisi tersebut. Kolom dictionary menyatakan string baru yang sudah ditambahkan ke dalam dictionary dan nomor indeks untuk string tersebut ditulis dalam kurung siku. Kolom output menyatakan kode output yang dihasilkan oleh langkah kompresi.

Proses dekompresi pada Lempel Ziv Welch (LZW) dilakukan dengan prinsip yang sama seperti proses kompresi. Tahapan dekompresi ditunjukkan pada Tabel II.

TABEL II

TAHAPAN PROSES DEKOMPRES

\begin{tabular}{|c|c|l|l|}
\hline \multicolumn{4}{|c|}{ TAHAPAN PROSES DEKOMPRESI } \\
\hline 1 & 1 & A & Dictionary \\
\hline 2 & 2 & B & {$[4]$ A B } \\
\hline 3 & 2 & B & {$[5]$ B B } \\
\hline 4 & 4 & A B & {$[6]$ B A } \\
\hline 5 & 7 & A B A & {$[7]$ A B A } \\
\hline 6 & 3 & C & {$[8]$ A B A C } \\
\hline
\end{tabular}

Prinsip umum kerja algoritma Lempel Ziv Welch (LZW) adalah mengecek setiap karakter yang muncul kemudian menggabungkan dengan karakter selanjutnya menjadi sebuah string jika string baru tersebut tidak berada dalam dictionary atau belum diindekkan maka string baru tersebut akan diindekkan ke dalam dictionary. Pseudocode kompresi algoritma Lempel Ziv Welch (LZW) dapat dilihat pada Gambar 1.

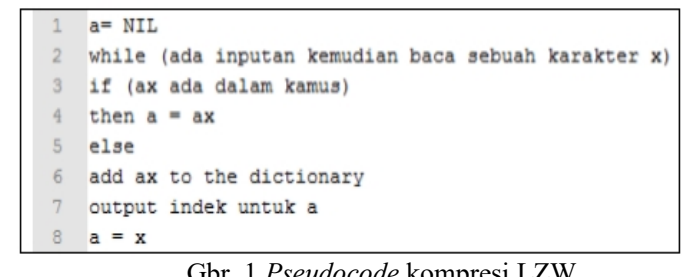

Dalam Proses Dekompresi, algoritma LZW tidak menyimpan string table yang berisi indek-indek dari setiap code word yang dihasilkan dalam proses kompresi ke memori akan tetapi menggunakan beberapa informasi yang telah disimpan sebelumnya antara lain 256 karakter ASCII, karakter pertama dari inputan dan code word terakhir. Di bawah merupakan 
pseudocode dekompresi algoritma Lempel Ziv Welch (LZW).

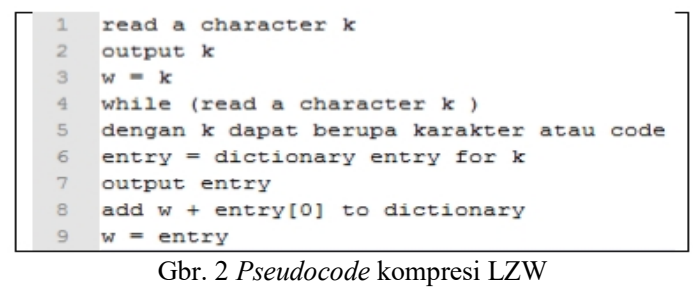

\section{METODOLOGI PENELITIAN}

\section{A. Rancangan enkripsi citra digital}

Rancangan proses enkripsi citra digital adalah sebagai berikut :

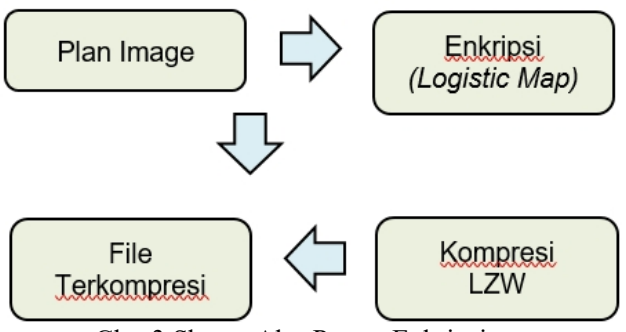

Gbr. 3 Skema Alur Proses Enkripsi

Berdasarkan gambar 3, langkah-langkah proses enkripsi yang akan dilakukan adalah sebagai berikut :

1. Penentuan plain-image berupa gambar atau citra yang akan dilakukan proses enkripsi.

2. Proses enkripsi dengan menggunakan algoritma Logistic Map. Proses enkripsi dengan skema XOR untuk masing-masing pixel dengan keystream (integer) (yang dibangkitkan dari Logistic Map dengan nilai awal $x_{0}$ dan parameter $\mu$ ). Proses enkripsi dapat dilakukan dengan persamaan (1).

3. Selanjutnya proses kompresi dilakukan dengan menggunakan algoritma kompresi lampel ziv welch.

4. Hasil dari proses diatas adalah file dengan ekstensi .mat.

B. Rancangan dekripsi citra digital

Rancangan proses dekripsi citra digital adalah sebagai berikut :

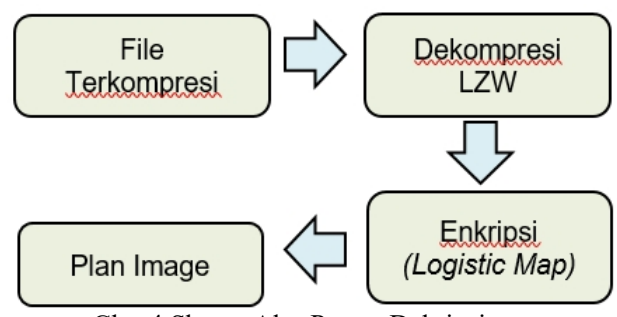

Gbr. 4 Skema Alur Proses Dekripsi

Berdasarkan gambar 4, langkah-langkah proses dekripsi yang akan dilakukan adalah sebagai berikut :

1. Pilih file terkompresi yang akan dilakukan proses dekompresi dan dekripsi
2. Dari file yang sudah dipilih akan dilakukan proses dekompresi, sehingga file akan berubah menjadi citra yang terenkripsi.

3. Selanjutnya proses dekripsi dilakukan dengan melakukan pengubahan nilai-nilai pixel dari cipher-image dengan menggunakan persamaan (1). Pixel-pixel dari cipher-image di XOR-kan dengan keystream (integer) (yang dibangkitkan dari Logistic Map dengan nilai awal $x_{0}$ dan parameter ).

4. Kemudian didapatlah citra semula (plainimage).

\section{HASIL DAN PEMBAHASAN}

Percobaan pada penelitian ini menggunakan Aplikasi Matlab R2012b dan Citra uji yang digunakan adalah citra grayscale dengan jenis citra bitmap. Citra uji yang digunakan adalah citra "lena.bmp" dengan dimensi 450 x 450 dengan ukuran 204.478 Bytes yang ditunjukan pada gambar 5 (a)

\section{A. Model Enkripsi Logistic Map}

Pada percobaan kedua akan dilakukan proses enkripsi dengan mengunakan algoritma logistic map. Dengan menggunakan persamaan (1) yang sudah dijelaskan pada bab sebelumnya (bab 2), akan dilakukan pengujian terhadap citra "lena.bmp";

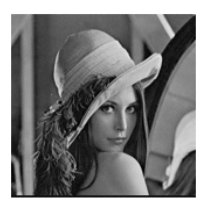

(a)

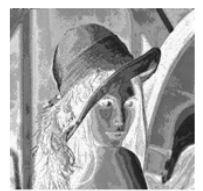

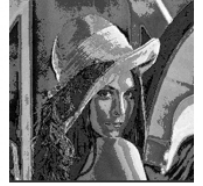

(b)

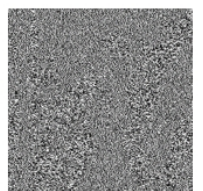

(d)
Gbr. 5 (a) Citra Asal ; (b) cipherimage dengan $\mathrm{xi}=0.7$ dan $\mu=1.5$; (c) cipherimage dengan $\mathrm{xi}=0.7$ dan $\mu=2.5$;

(d) cipherimage dengan $x i=0.7$ dan $\mu=4$.

\section{B. Gabungan Kompresi dan Enkripsi dari Citra} Digital

Pada percobaan ini akan dilakukan proses kompresi terhadap hasil enkripsi (cipherimage) dari algoritma logistic map. Proses kompresi akan dilakukan dengan menggunakan algoritma Lempel Ziv Welch (LZW) yang nantinya hasil dari kompresi akan disimpan dalam bentuk variabel. Variable enkripsi akan disimpan dalam direktori penyimpanan dalam bentuk file dengan ektensi MAT (.mat). 


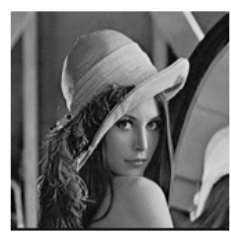

(a)

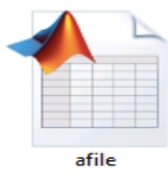

(c)

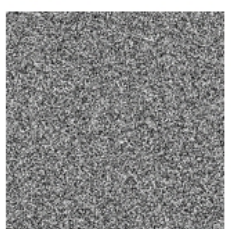

(b)
Gbr. 6 (a) Citra Asal ; (b) cipherimage dengan logistic map ;

(c) file hasil kompresi terhadap citra hasil enkripsi.

\section{Analisis Histogram}

Histogram merupakan salah satu fitur citra yang penting, sebab sebuah histogram memperlihatkan distribusi intensitas pixel-pixel di dalam citra tersebut. Dalam melakukan serangan dengan teknik analisis statistik, penyerang menggunakan histogram untuk menganalisis frekuensi kemunculan intensitas pixel untuk mendeduksi kunci atau pixel-pixel di dalam plain-image. Agar serangan dengan analisis statistik tidak dimungkinkan, maka di dalam enkripsi citra penting untuk menghasilkan histogram cipher-image yang tidak memiliki kemiripan secara statistik dengan histogram plain-image. Oleh karena itu pixel-pixel di dalam cipher-image seharusnya memiliki distribusi yang (relatif) uniform atau ditunjukkan dengan histogram yang terlihat datar (flat).

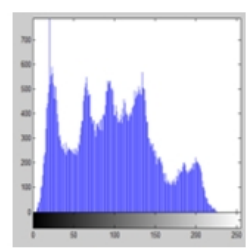

(a)

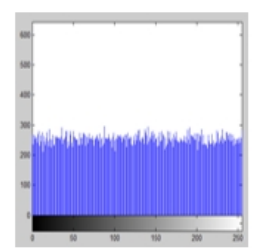

(b)
Gbr. 7 (a) Histogram Citra asal (lena.bmp);

(b) Histogram Citra hasil enkripsi algoritma Logistic Map

Dari gambar 7 menunjukan perubahan yang signifikan antara histogram citra asal dengan citra hasil enkripsi. Terdapat banyak perubahan intensitas pixelpixel didalam citra yang dienkripsi. Walaupun begitu, enkripsi hanya menggunakan algoritma logistic map saja tidak cukup aman bagi keamanan pesan citra dikarenakan kita harus menyimpan kunci yang telah dibangkitkan kedalam proses enkripsi. Hal ini membuat pesan citra mudah dipecahkan oleh pihakpihak yang tidak berhak.

\section{Analisis Sensitivitas}

Pada analisis ini akan dilakukan perubahan nilai awal $\left(x_{0}\right)$ pada algoritma logistic map dalam melakukan proses dekripsi untuk mengetahui sensitivitas chaos terhadap nilai awal. Pada penelitian ini akan dilakukan perubahan nilai awal $\left(x_{0}\right)$ dengan menambahkan nilai sebesar $\alpha$ sehingga menjadi $x_{o}+\alpha$. Dimisalkan nilai $\alpha=10^{-15}$, sehingga nilai awal menjadi 0.200000000000001

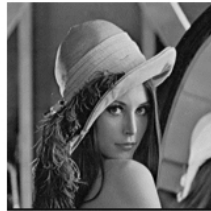

(a)

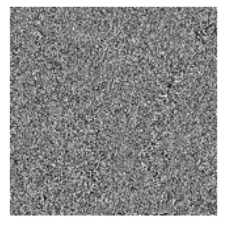

(b)

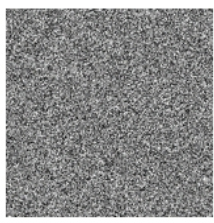

(c)
Gbr. 8 (a) Citra asal (lena.bmp);

(b) Hasil enkripsi dengan nilai awal $\left(x_{o}\right)=0.2$;

(c) Hasil dekripsi dengan nilai awal $\left(x_{o}\right)=0.200000000000001$.

Pada gambar 8 Terlihat bahwa proses dekripsi dengan nilai awal $=0.200000000000001$ tidak mengembalikan citra ke citra asal. Citra hasil dekripsi masih terlihat acak, itu membuktikan bahwa chaos memenuhi prinsip defussion dari shanon (Schneier, 1996). Sehingga kriptanalis sulit untuk memecahkannya karena perubahan satu bit saja pada kunci menyebabkan hasil dekripsi tetap salah.

\section{E. Analisis Perubahan Nilai Pixel pada Matrix Citra}

Hasil dari kompresi terhadap citra terenkripsi (cipherimage) pada penelitian ini disimpan dalam bentuk file matlab dengan ekstensi (.mat). Proses kompresi terhadap file hasil enkripsi bukan hanya dapat merubah posisi pixel didalam citra tetapi juga merubah matrix citra menjadi vector, sehingga hasil dari kompresi tidak lagi berbetuk citra tetapi berbentuk file bukan citra. Berikut gambar perubahan matriks pada citra "Lena.bmp" berukuran 450 × 450 dari citra asal, citra terenkripsi (cipherimage) dan citra sesudah proses kompresi. 


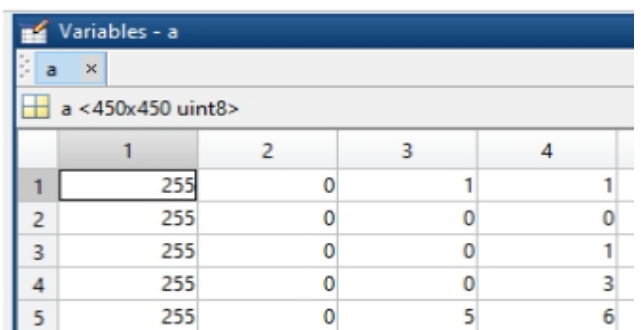

Gbr. 9 Posisi dan nilai pixel dari citra asal (lena.bmp) dalam bentuk matriks

Gambar 9 menunjukkan sebagian posisi dan nilai pixel dari citra asal (Lena.bmp) dalam bentuk matriks sebelum dilakukan proses enkripsi dan kompresi. Nilai pixel dari citra akan mengalami perubahan setelah dilakukan proses enkripsi dengan menggunakan algoritma logistic map. Perubahan nilai pixel tersebut seperti ditunjukan pada gambar 10 dibawah ini.

\begin{tabular}{|c|c|c|c|c|}
\hline \multicolumn{5}{|c|}{ af Variables - e } \\
\hline$\because e$ & & & & \\
\hline \multicolumn{5}{|c|}{ 田 $\mathrm{e}<450 \times 450$ uint $8>$} \\
\hline & 1 & 2 & 3 & 4 \\
\hline 1 & 79 & 54 & 81 & 251 \\
\hline 2 & 58 & 148 & 91 & 181 \\
\hline 3 & 115 & 230 & 112 & 168 \\
\hline 4 & 91 & 197 & 53 & 246 \\
\hline 5 & 232 & 66 & 22 & 12 \\
\hline
\end{tabular}

Gbr. 10 Posisi dan nilai pixel dari citra terenkripsi (cipherimage) dalam bentuk matriks.

Gambar 10 menunjukkan perubahan nilai pixelpixel dalam citra setelah dilakukan proses enkripsi dengan menggunakan algoritma Arnold cat map dan logistic map. Selajutnya proses kompresi pada citra terenkripsi (cipherimage) akan merubah posisi pixelpixel pada citra dari matrix menjadi vector. Hasil perubahan tersebut ditunjukan pada gambar 11 dibawah ini.

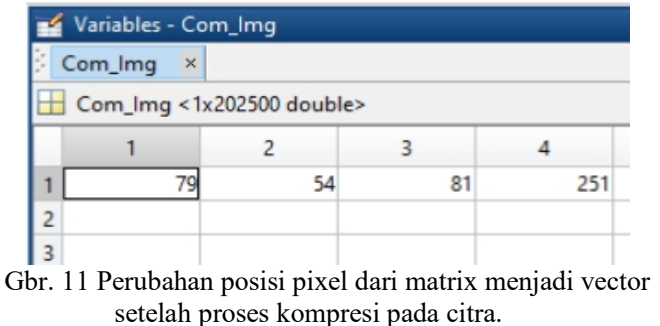

Gambar 11 menunjukkan hasil perubahan posisi pixel-pixel pada citra dari bentuk matriks menjadi bentuk vector. Hasil proses kompresi yang membuat perubahan posisi pixel, menjadikan file citra hasil kompresi tidak dapat disimpan dalam bentuk citra kembali. Dalam penelitian ini hasil kompresi dari citra disampan dalam bentuk file matlab dengan ekstensi.mat. Selain itu, perbedaan format file hasil enkripsi juga menjadi unsur penting dalam kriptografi. Penerapan teknik kompresi pada hasil enkripsi (cipherimage) dapat membantu menghindari perhatian kriptanalisis karena perbedaan file yang dihasilkan dari file citra menjadi file matlab yang berekstensi .mat
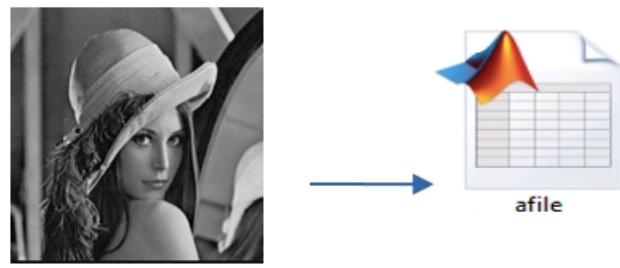

\section{(*.bmp ) (*.mat )}

Gbr. 12 Perubahan ekstensi file citra menjadi file .mat

\section{KESIMPULAN}

Penelitian dan percobaan yang telah dilakukan menghasilkan kesimpulan sebagai berikut:

1. Hasil penelitian menunjukan bahwa model enkripsi menggunakan algoritma berbasis chaos yaitu algoritma Logistic map pada citra digital dapat menghasilkan citra acak yang sudah tidak dapat dikenali lagi.

2. Sensitivitas dari algoritma Logistic Map menunjukan prinsip defussion, walau perbedaannya hanya 0,000000002 citra tidak kembali ke citra semula.

Penggunaan teknik kompresi pada citra hasil enkripsi (cipherimage) menghasilkan perubahan matrix pada citra menjadi vector, sehingga file yang dihasilkan berupa file bukan citra (.mat).

\section{REFERENCE}

[1] Irfan,P., Prayudi, Y., \& Riadi, I. 2015. Image Encryption using Combination of Chaotic System and Rivers Shamir Adleman (RSA). International Journal of Computer Applications (0975 - 8887), pp. 11-16.

[2] Neta, M.R.A. 2013. Perbandingan Algoritma Kompresi Terhadap Objek Citra Menggunakan JAVA. Prosiding Seminar Nasional Teknologi Informasi \& Komunikasi Terapan 2013 (Semantik 2013), pp. 224-230.

[3] Munir, R. 2012. Algoritma Enkripsi Citra Digital Berbasis Chaos Dengan Penggabungan Teknik Permutasi dan Teknik Substitusi Menggunakan Arnold Cat Map dan Logistic Map. Prosiding Seminar Nasional Pendidikan Teknik Infomatika (SENAPATI 2012), pp. 107-124.

[4] Fdsaf Sharma, M. 2010. Image Encryption Techniques Using Chaotic Schemes: A Review. International Journal of Engineering Science and Technology 2(6), pp. 23592363.

[5] Chang, C.-C., Hwang, M.-S \& Chen, T.-S. 2001. A New Encryption Algorithm For Image Cryptosystems. The Jurnal Of Systems And Software 58 : 83-91. 